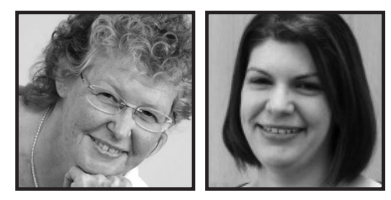

\title{
The Glow of Unwork? Issues of Portrayal in Arts-Related Research
}

\author{
Maggi Savin-Baden, University of Worcester \\ Gemma Tombs, Coventry University
}

\begin{abstract}
In this paper we argue that arts-related research provides greater or diverse opportunities to represent and portray data differently and suggest that these ways are underutilized. For example, for many researchers legitimacy comes through the use of participants' voices in the form of quotations. However, we argue that this stance towards plausibility and legitimacy is problematic and needs to be reconsidered in terms of understanding differences in types of portrayal, recognizing how researchers position themselves in relation to portrayal, and understanding decision-making in relation to portrayal.
\end{abstract}

1 ortrayal is often seen as an issue that is relatively straightforward by qualitative researchers, and invariably refers to putting the findings of the study together with excerpts from participants and usually, but not always, some interpretation. In this paper, we suggest that portrayal in arts-related research is often undervalued and seen as "unwork" (Galloway, 2012). Portrayal tends to be seen as the means by which the researcher has chosen to position people and their perspectives, and it is imbued with a sense of not only positioning, but also a contextual painting of a person in a particular way. Yet, there is an array of issues and challenges about what portrayal can or might mean in arts-related research. We suggest that there needs to be new perspectives about portrayal and concept, and ideas are provided that offer a different view. Three key recommendations are made: 
- Portrayal should be reconceptualised as four overlapping concepts: mustering, folding, cartography, and portrayal. Adopting such an approach will enable audiences, researchers, and other stakeholders to critique the assumptions that researchers on tour bring to portrayal and encourage reflexivity.

- Researchers on tour should highlight the temporal, mutable, and shifting nature of portrayed research findings, emphasizing the need for continued and varied research to inform understanding.

- There is a significant need for greater insight into the influence of portrayal, as well as the difference between representation and portrayal. Future studies should prioritize this, and ensure that portrayal is considered and critiqued from the outset.

\section{Background}

Portrayal of research findings has often been seen as unproblematic, yet authors such as St. Pierre $(2008,2009)$ and Butler-Kisber $(2002,2008,2010)$ indicate it is invariably much more troublesome than most researchers acknowledge. We suggest that there is often friction between the interfaces or boundaries among interpretation, representation, and portrayal. Galloway (2012) argues that it is difficult to see friction at the interfaces, since, for the most part, they are designed to be invisible. Thus, work done at an interface renders the interface invisible, in order to make it work effectively. It then appears that no work has or is taking place, and thus the interfaces cast what he calls, "the glow of unwork" (p. 25). Perhaps, when undertaking educational work in arts-related research, we need to give greater attention to what is occurring at the interfaces, particularly between representation and portrayal. There is a need to recognize that students and young people centre their lives on networked publicsspaces that are created, structured, and restructured around networked technologies and that these are further sets of fractioned fractures and swirling interfaces that affect representation and portrayal of findings. Thus, we need to explore what is privileged and what is missing, to examine what has been created and crafted, and to recognize how frictions and fractures at these interfaces can improve our understandings and make us better, braver researchers. Portrayal is defined here as the contextual painting of a person or data set in a particular way. However, many research studies use the terms "representation" and "portrayal" interchangeably. For example: 
- Representation tends to refer to the way in which a researcher provides warranted accounts of data collected. Thus, the main way the term representation is used is in the sense of a proxy, the researcher is (re)presenting the views of the participants. This is often seen or presented by the researcher as being unproblematic. Yet researchers need to acknowledge and voice that the research account they are providing does in fact reflect their own stance and position. We suggestthat often personal stances and accounts are missing from research data and this is seen most often when undertaking qualitative research synthesis (Savin-Baden \& Major, 2010).

- Portrayal invariably is seen as the means by which the researcher has chosen to position people and their perspectives. Portrayal tends to be imbued with a sense of not only positioning, but also a contextual painting of a person in a particular way.

Those who do use "portrayal" invariably are referring to media (mis)representation of particular groups: women, Muslims, black youth. We argue that research portrayal, and particularly qualitative research portrayal, should centre not only on how something is restated, but also how they are depicted by researchers. Thus, what is central to portrayal is in-depth interpretation, which involves examining the subtext and exploring what is being argued for by those in the study by interpreting, for example, metaphors, metonymy, and oppositional talk. There is no sense of quick coding and analysis in this process, but rather as St. Pierre (2009) has argued:

I believe we have burdened the voices of our participants with too much evidentiary weight. I suggest we put voice in its place as one data source among many from which we produce evidence to warrant our claims and focus for a time on other data we use to think about our projects that we've been ignoring for decades. (p. 221)

Jackson and Mazzei (2011) suggest that in the analytical process, the researcher and the researched are both subject to change, as is the audience or viewer, so that as the research data are transformed and offer something else, something new is made available: a new portrayal of the phenomena. This stance places portrayal as somehow less static and acknowledges the importance of the interaction between researcher and participants. Portrayal then needs to be seen as a process, rather than an ending, as Butler-Kisber (2002) suggests: "A portrayal presents the essence of a phenomenon at a certain time while retaining the signature of the creator. Artful portrayals mediate understanding, our own and that of others" (p. 238). 
Yet, the spaces in which research data is portrayed, are also important. Lefebvre (1991) has suggested that social space might be seen as comprising a conceptual triad of spatial practice, representations of space, and representational spaces. Spatial practice represents the way in which space is produced and reproduced in particular locations and social formations and we suggest it has strong links with portrayal. The work of Harrison (2013) is a useful example of a moving portrayal of space. In the excerpt below, he discusses how he created a circus tent as a means of representation, performance, and portrayal:

As an Artist-in-Residence in a Toronto District School Board high school I began my research. This involved setting up an open door studio through which students could come and go ongoing through the process of the research. An autoethnographic, arts informed project was begun in which I would explore the narratives of my own life as a lens into growing up gay in rural Ontario in the 1960s and 1970s. The dissemination of the findings was achieved through painting on the walls of a small circus or freak show tent. Images on the outside of the tent were appropriated from Ringling and Barnum Bailey's circus and freak show advertisements and historical photographs (Jando et al, 2008) intertwined with self-portrait images of the more negative ways I am imagined as a gay man. On the inside walls of the tent autoethnographic images were painted which explore the formative years of my life and how I imagined myself. The painted freak show tent is the dissertation. An artist's catalogue was created documenting the studio, the research conducted to produce the narratives, the creation of the tent and the tent itself. It became the document that with the tent itself could be defended to conclude my doctoral research, for it both documented and contextualized the cultural artifact (Lyman \& Kale, 1998) of the tent.

What is significant about Harrison's work is that the work is used to enhance understanding, and to reach multiple audiences. The interfaces of representation and portrayal interrupt ideas of data presentations as well as use media to make research findings accessible to a variety of people.

\section{Concepts of Portrayal}

However, whilst space is a significant consideration, the processes involved in "portrayal creation" are also important. We suggest that portrayal can be delineated as four overlapping concepts-Folding, Mustering, Cartography, and Assemblage: 


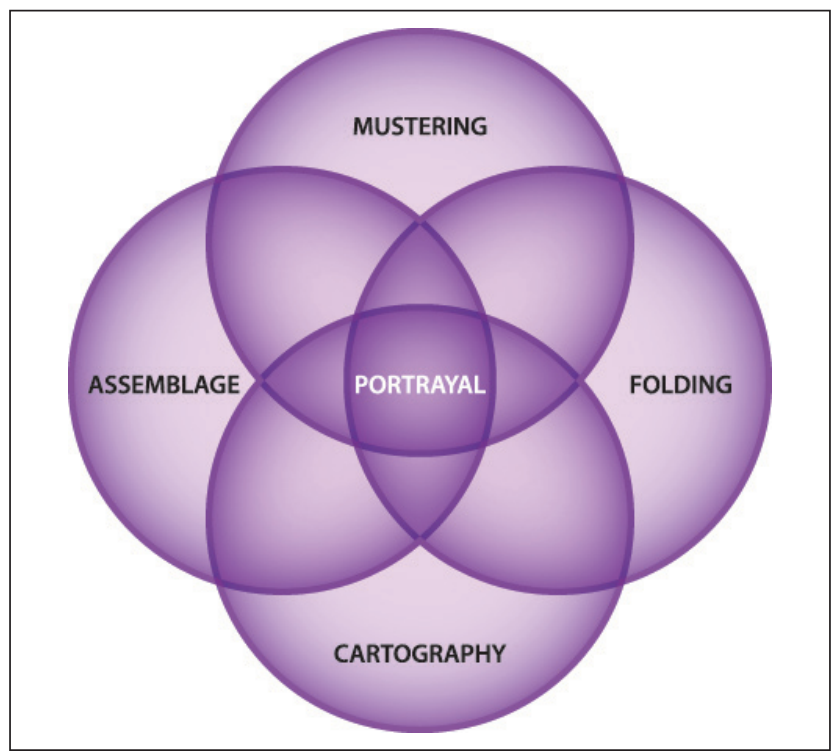

Fig. 1: Concepts of portrayal

\section{Mustering}

Mustering is a term often used to gather troops for battle and this has resonance here, in that researchers gather themselves, gird their thoughts and ideas, and begin the portrayal process. Mustering then is the part of the portrayal process where data are brought together and decisions are made about how they will be used in the act of portrayal. It involves making decisions about voice, colour, text, what is to be included, and how to account for what is to be. There is a sense of living and working with order and chaos simultaneously. What emerges is an appreciation that what was once frayed meaning becomes a holistic depiction which is both fragile and portrayed. This mustering is influenced to a degree by the folding process.

\section{Folding}

The notion of folding (Deleuze, 1993) disrupts the idea of data being portrayed as straightforward and one-dimensional. The idea of a fold helps us to see portrayal as a means of being and becoming part of the data and its endings. Folding allows for a multiplicity of portrayal whilst helping readers see some kind of sense in the findings, as well as possible continuities and labyrinths with other research: 
Thus a continuous labyrinth is not a line dissolving into independent points, as flowing sand might dissolve into grains, but resembles a sheet of paper divided into infinite folds or separated into bending movements, each one determined by the consistent or conspiring surrounding ... A fold is always folded within a fold, like a cavern in a cavern. The unit of matter, the smallest element of the labyrinth, is the fold, not the point which is never a part, but a simple extremity of the line. (p. 6)

Folding means there is disruption between the idea of an inside and an outside so that inside and outside are both inside and outside; to reiterate: "a fold is always fold within a fold" (p. 6). Thus, there is recognition by the researcher that data, findings, and interpretations are neither stable, nor do they offer a singular view. In the context of portrayal, using the concept of folding imbues the portrayal of findings with the idea that there are necessary complexities and complexities are necessary. What is seen and portrayed is not distinct or fixed, but is complex, disrupting, changing, and fluid.

\section{Cartography}

Cartography is defined as the study and practice of making maps. The process and action involved in cartography has similarities with the ways data are managed and especially portrayed in qualitative research, in that cartographers must make decisions about how to portray geographical data. The changes in technology have meant that cartography has a role both in the creation of physical maps and in the graphical presentation of geospatial information about the environment and people. For de Certeau (1984), maps are static and fixed, used by us to denote representations of how we live; tours, on the other hand, portray how we live, how we move about within the spaces in which we live. Yet, we maintain that the digital age has resulted in a merger of maps and tours as portrayed by de Certeau. We suggest instead that, at a number of different levels researchers are cartographers on tour who collect, co-construct, represent, and then portray data-sometimes in ways that are troublesome and messy, and at other times that are tidy, manageable, and managed.

\section{Assemblage}

This notion of portrayal is the idea that data are collected and constructed from different sources and points in time in order to assemble relatively whole (rather than partial) depictions of participants and their lives, contexts, and stories. Assemblage then is not some kind of snapshot, something that is cut from data and re-created from data. Rather, assemblage is the creation of a holistic description of the research and the people involved as possible. Assemblage includes the assembling of words, 
pictures, reflections from theorists, friends, tweets, and ideas. Portrayal in this sense is the bringing together of all the influences that have an impact on the researcher as they saw, interpreted, and created the portrayal of the findings of the study.

\section{Portrayal of Data in Arts-Related Research}

In order to portray data from arts-related research, researchers muster themselves to consider what it is they wish to portray, acknowledging that data are folded. Further, they also need to acknowledge that in choosing to portray data means also choosing to exclude data, even if that portrayal of data is an assemblage from multiple sources. This process, from a "researcher on tour," can be likened to the creation of a liquid map. Researchers on tour take with them their subtextual assumptions and inferences, often presenting the illusion of a reflexive stance whilst portraying findings as static and immutable. It is that illusion we wish to challenge.

The issue of data portrayal in the digital domain has gained increasing traction in recent years. For example, the AHRC-funded Seeing Data Project is currently examining public responses to data visualisations and especially the effectiveness of "big data" visualizations. Whilst there are many different forms of data visualizations, the company, Daden, UK has created Datascape that provides an easy-to-use immersive $3 \mathrm{D}$ environment in which you can visualize and interact with data from almost any source. Datascape is designed to maximize human analysis by optimizing the display of data, whether structured or unstructured, enabling a wide variety of viewpoints to be taken from both inside and outside the data. Another example can be seen in the Seeing Data project. Seeing Data is a research project that aims to understand how people make sense of data visualizations. There is more and more data around us, and data are increasingly used to explain our social world. One of the main ways that people get access to data (big and small) is through visualizations, like those on the pages of a website. Visualizations are visual representations of data. They are used to help people make sense of data or to allow people to explore data. They take the form of graphs, charts, and other more complex or less familiar diagrams.

Visualizations appear in newspapers, on television (especially in documentaries and news programs), and on the Internet in social media like Facebook. What we don't know is how people make sense of visualizations. How do we interact with them? How do we interpret them? Do they help us make sense of data? Do different people interact with visualizations in different ways? What messages do we take 
away from visualizations? On the Seeing Data project we have been exploring these questions and finding out what skills people need to help them to make sense of visualizations. (Seeing Data Project, 2016)

These visualisations, as Yau (2013) has suggested, are not just tools to present data, but also entirely new visual mediums. Such visualisations, "offer the means to see data as a material able to exist at many different levels of granularity with different levels of depth and resolution" (Thrift, 2014, p. 8). Studies in the field of education have paid particular attention to visualizing "big data" and learning analytics data, and portraying it in a manner that is most helpful to students (Duval, 2011; Olmos \& Corrin, 2012), although less attention has been paid to the ways in which data is portrayed in public research findings. Techniques such as Wordles, social network diagrams, tag clouds, tweets portrayed using Storify, and infographics are also popularized across the sector, and it therefore seems likely that mobile social media tools which convey connections across individuals and groups might increasingly be used to portray arts-related research data. Cochrane (2015), for example, has argued for the use of mobile social media tools such as TAGSExplorer in collaborative research and thus, potentially, data portrayal.

Such tools still require researchers to consider the four concepts of portrayal, however. For example, social network diagrams can portray connections across and within groups, but do not account for the quality or content of those connectionsif this is important to the data, how can this best be portrayed to be considered equally important by the audience? Similarly, Wordle has been found to be useful for analysis, but lacking context essential for interpretation and portrayal (McNaught \& Lam, 2010). Storify is a tool that is used to curate Twitter conversations, but requires its users to make decisions about which tweets to use, which to exclude, and how to present networked conversations-in essence, to muster themselves and their data. Where digital portrayal is different, however, is in its vast potential to allow audiences to interact with data. Digital portrayals of data such as the OECD Better Life Index (OECD, 2015) can be personalized for the audience, challenging the notion that data is static and immovable, and highlighting the mutable, folded, and situated nature of research findings. 


\section{Recommendations}

We suggest that in order for portrayal to be acknowledged as key in the understanding of arts-related research findings, the following recommendations should be considered:

1. Portrayal should be reconceptualized as four overlapping concepts: mustering, folding, cartography, and portrayal. Adopting such an approach will enable audiences, researchers, and other stakeholders to critique the assumptions that researchers on tour bring to portrayal and encourage reflexivity.

2. Researchers on tour should highlight the temporal, mutable, and shifting nature of portrayed research findings, emphasizing the need for continued and varied research to inform understanding.

3. There is a significant need for greater insight into the influence of portrayal, as well as the difference between representation and portrayal. Future studies should prioritize this, and ensure that portrayal is considered and critiqued from the outset.

\section{Conclusion}

Whilst portrayal in arts-related research is often seen as "unwork," we suggest the need for more candid forms of portrayal; forms in which researchers cannot hide behind the subtext of their own agendas, comfort zones, and biases. By using mustering, folding, cartography, and assemblage, the portrayal of our research findings may be more unconformable and messy, but possibly more honest. Representation and portrayal are processes and practices that tend to leave behind trails of earlier versions. Most of these are hidden in the dustbins of our homes and computers, and ignored as no longer valuable, even if they have been central to the mustering and assemblages of our findings. If we are to be researchers who wish to present plausible accounts of our findings, we need to examine these trails, particularly exploring what has been cast aside or missed. At the same time, researchers need to be aware of the importance of the interfaces between interpretation of data and the ways they are subsequently (over)managed, represented, and portrayed. 


\section{References}

Butler-Kisber, L. (2002). Artful portrayals in qualitative inquiry: The road to found poetry and beyond. The Alberta Journal of Educational Research, 48(3), 229-239.

Butler-Kisber, L. (2008). Representational forms of dissemination. In L. Given (Ed.), The Sage Encyclopedia of Qualitative Research, 2, (pp. 756-760). Thousand Oaks, CA: Sage.

Butler-Kisber, L. (2010). Qualitative inquiry: Thematic, narrative and arts-informed perspectives. London: Sage.

Cochrane, T. (2015). Updating the scholarship of teaching and learning: Boyer for the Post Web 2.0 age. Retrieved from http://bit. ly/1MFJsVR

de Certeau, M. (1984). The practice of everyday life. (Trans. by S. Rendall). Berkeley: University of California Press.

Deleuze, G. (1993). The fold: Leibniz and the baroque. (Trans. by T. Conley). New York: Continuum.

Duval, E. (2011). Attention please!: Learning analytics for visualization and recommendation. In S. Buckingham Shum, D. Gasevic, \& R. Ferguson. Proceedings of the 1st International Conference on Learning Analytics and Knowledge (pp. 9-17). New York: ACM.

Galloway, A. R. (2012). The interface effect. Cambridge: Polity Press.

Harrison, S. J. (2013). Not a freak show: Growing up gay in rural Ontario in the 1960s without narratives, images or role models upon which to formulate an identity. Paper presented at AERA Annual Meeting and Exhibition, San Francisco, CA, 27th Apr - 1st May 2013.

Jackson, A. Y., \& Mazzei, L. A. (2011). Thinking with theory in qualitative research: Using epistemological frameworks in the production of meaning. London: Routledge.
Jando, D., Sabia, R. F., \& Daniel, N. (2008). The circus: 1870-1950. Köln, Germany: Taschen.

Lefebvre, H. (1991). The production of space, 15th ed. Oxford: Blackwell.

Lyman, P., \& Kahle, B. (1998). Archiving digital cultural artifacts: Organizing an agenda for action. D-lib Magazine, 7/8. Retrieved from http://www.dlib.org/dlib/july98/07lyman. html

McNaught, C., \& Lam, P. (2010). Using Wordle as a supplementary research tool. The Qualitative Report, 15(3), 630-643.

Olmos, M. M., \& Corrin, L. (2012) Learning analytics: A case study of the process of the design of visualizations. Journal of Asynchronous Learning Networks, 16(3), 39-49.

Organisation for Economic Co-Operation and Development Better Life Index. (2015). Retrieved from http://www.oecdbetterlife index.org

Savin-Baden, M., \& Major, C. (2010). An introduction to qualitative research synthesis: Managing the information explosion in social science research. London: Routledge.

Seeing Data Project. (2016). Retrieved from seeingdata.org

St. Pierre, E.A. (2008). Decentering voice in qualitative inquiry. International Review of Qualitative Research, 1(3), 319-336.

St. Pierre, E. (2009). Afterword: Decentering voice in qualitative inquiry. In A. Y. Jackson \& L. A. Mazzei (Eds.), Voice in Qualitative Inquiry. (pp. 221-236). London: Routledge.

Thrift, N. (2014). The 'sentient' city and what it may portend. Big Data and Society, 1(1), 1-21.

Yau, N. (2013). Data points. Visualization that means something. Indianapolis: John Wiley and Sons. 


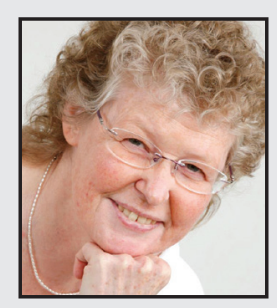

Maggi Savin-Baden is Professor of Education at University of Worcester and has researched staff and student experience of learning for over 20 years and gained funding (Leverhulme Trust, JISC, MoD) to research the effectiveness of learning in new electronic and immersive spaces. She is an experienced writer on research methodologies and an expert in the development of innovative and creative learning scenarios. Maggi has published over 50 research publications and 13 books, and is currently writing two more. In her spare time she runs, rock climbs, and attempts to be a triathlete.

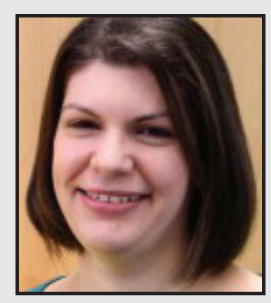

Gemma Tombs is a Research Associate at the Disruptive Media Learning Lab at Coventry University. Her research focuses on pedagogical design for educational technologies, and particularly the ways in which staff adapt, adopt, and develop pedagogy, and the support they require when doing so. Gemma is an Associate Fellow of the Higher Education Academy and a reviewer for several educational journals, including Computers and Education. She has 11 peer-reviewed publications, with one more shortly forthcoming and has just completed her first book, titled, Research Methods for Education in the Digital Age, with Maggi Savin-Baden. 